\title{
Environmental impacts of new Coronavirus outbreak in Iran with an emphasis on waste management sector
}

\author{
Ali Daryabeigi Zand ${ }^{1} \cdot$ Azar Vaezi Heir ${ }^{1}$
}

Received: 20 July 2020 / Accepted: 23 September 2020 / Published online: 3 October 2020

○) Springer Japan KK, part of Springer Nature 2020

\begin{abstract}
The COVID-19 pandemic have brought several environmental problems worldwide, among which management of municipal solid wastes (MSW) is of great importance due to the effects of solid wastes on soil, air and water resources. This research focused on the emerging challenges in MSW management in Tehran, the capital of Iran, during the COVID-19 pandemic. Tehran has been experiencing higher generation of MSW during the pandemic. Extensive use of personal protective equipments increased textile and plastic wastes considerably. On average, more than 4.5 million pieces of facemasks have been daily discarded by Tehranian residents during the COVID-19 pandemic. Generation of hospital wastes in Tehran also increased by $17.6-61.8 \%$ during the pandemic. Legal source separation and recycling programs are still suspended, though waste collection procedure in Tehran has not been subjected to significant changes after the outbreak of the Coronavirus. Hospital wastes, which had been partially separated and treated, are now being collected altogether and landfilled. Waste incineration and composting have been ceased completely; therefore landfilling of MSW has increased by 35\% and opted as the only disposal option in Tehran during the COVID-19 outbreak. This research represents a baseline to devise proper urban waste management strategies in developing countries during the COVID-19 pandemic.
\end{abstract}

Keywords COVID-19 $\cdot$ Municipal solid waste $\cdot$ Medical waste $\cdot$ Treatment $\cdot$ Disposal

\section{Introduction}

COVID-19 pandemic has changed people life style, quantity and quality of generated wastes, and waste management operations in most developing countries. As of July 18,2020 , there had been 14,205,416 confirmed cases and 599,716 deaths worldwide, with 269,440 confirmed cases and 13,791 deaths reported in Iran due to the COVID-19 outbreak [1]. The WHO named that a global pandemic on March 11, 2020 due to the rapid outbreak of the disease worldwide [2]. Coronaviruses are a large family of viruses having single-stranded RNA and a crown on their surface. These viruses are greatly pathogenic to humans, posing illness ranging from the common cold to severe diseases such as respiratory infection and gastrointestinal diseases [3, 4]. The new Coronavirus (COVID-19), which was initially

Ali Daryabeigi Zand

adzand@ut.ac.ir

1 School of Environment, College of Engineering, University of Tehran, No. 25, Azin St., Qods St., Enghelab Ave., 141556135 Tehran, Iran reported in December 2019, caused numerous cases of pneumonia of unknown etiology followed by severe acute respiratory syndrome in Wuhan City, China. Afterwards, the COVID-19 has rapidly spread all around the world [5]. Recent statistics on COVID-19 infected cases and deaths in Iran are shown in Fig. 1. It can be known from the Fig. 1 that the number of infected cases in Iran increased rapidly from 2282 cases on 30 May 2020 to hit a plateau of 3574 cases on 04 June 2020, which mainly caused by the reopening strategy for several businesses and jobs, unsafe travelling during the COVID-19 pandemic, and the lack of public attention to social distancing guidelines. Tehran is among the mostly affected cities in Iran by the COVID-19 pandemic economically and socially. COVID-19 infected cases in Tehran account for a large number of confirmed cases in Iran; however, the Ministry of Health and Medical Education of Iran decided to declare only the total number of COVID-19 infected cases and deaths in Iran and revealing the provinceby-province statistics were prohibited since mid-April. In Tehran, totally 5092 infected cases were reported between 23 February 2020 and 22 March 2020, constituting ca. 

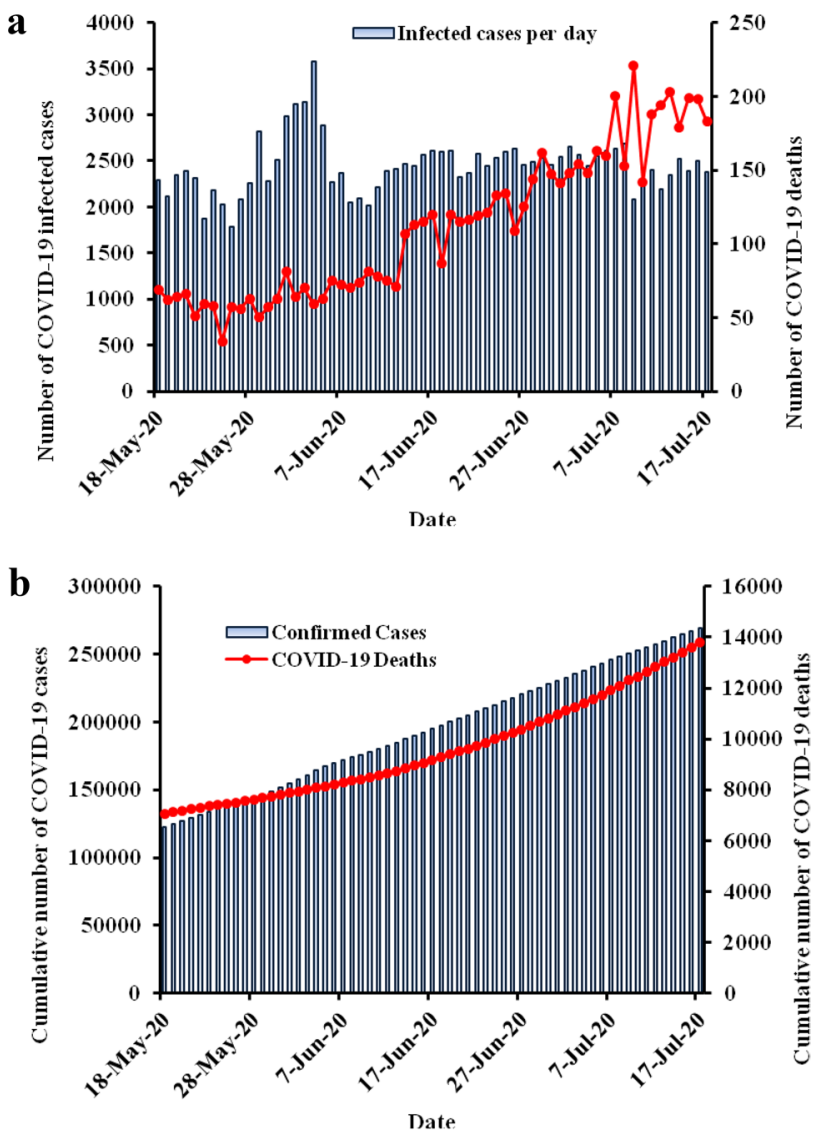

Fig. 1 Daily (a) and cumulative (b) confirmed infection cases and deaths in Iran between 18 May 2020 and 17 July 2020 due to the COVID-19 pandemic. Raw data adapted from Worldmeters (2020) [17]

$23.6 \%$ of the total infected cases in Iran during that period (1st rank in the country).

Urban solid waste management has long been recognized as a serious environmental issue in developing countries including Iran. Non-sustainable handling of wastes in many developing countries makes them more vulnerable to the possibility of Coronavirus propagation through waste management practices [6]. For instance, in Iran, solid wastes are usually dumped or buried in poorly managed landfills where waste pickers without proper personal protective equipments (PPEs) could scavenge for recyclable materials. In Iran, the 18th most populated country in the world with over 81 million people; annually more than 18 million tonnes of MSW are generated. Source reduction and separation programs are poorly implemented throughout the country, with only $8 \%$ MSW recycling through legal framework [7]. Hazardous household wastes such as paint, electronic wastes, and medical wastes are not usually separated at homes, therefore mixed with general household wastes. Collection and disposal of non-segregated household wastes may pose serious environmental and human health problems. Urban wastes should be considered as a potential serious threat for human health since non-proper handling and disposal of them can spread the Coronavirus extensively. To our knowledge, the impact of COVID-19 pandemic on municipal solid waste management has little been studied in developing countries. The effects of COVID-19 pandemic on waste management situation in Tehran is addressed for the first time in this study. This research aims to show the emanating challenges of urban waste management in Tehran during the COVID-19 pandemic. Pragmatic approaches to improve waste management practices in Tehran during the COVID-19 pandemic are presented, which can be used as a baseline in devising proper waste management policies in developing nations during the Coronavirus era.

\section{Materials and methods}

COVID-19 pandemic is a sensitive issue in most countries that makes it difficult for researchers to extract required information on the effects of COVID-19 outbreak on the environment, especially in developing countries. For instance, the total number of infected cases, recovered cases and deaths is the only official statistics that is declared by the Ministry of Health and Medical Education of Iran regarding the COVID-19. However, it is necessary to have appropriate information regarding solid waste situation in the capital city of Tehran to be able to analyze the new challenges caused by the pandemic and properly manage the emerging problems in waste management sector during the COVID-19 outbreak. In such a situation, close contact with district municipalities is required to assess the present status of solid waste management in Tehran. A questionnaire was prepared and distributed among 8 district municipalities of Tehran. The questionnaire focused on four aspects: MSW generation, collection and disposal as well as handling of hospital wastes. In addition to the district municipalities, some faculty members, environmental experts and scientists were also interviewed. Randomly selected waste collection teams were also interviewed face-to-face. Fortunately, most of the respondents and interviewees showed their sympathy with the significance of proper solid waste management in Tehran during the COVID-19 pandemic; however, they mainly preferred to disclose qualitative information regarding MSW situation in Tehran rather than quantitative information. Important information was found in this investigation that would also be beneficial for other developing countries with similar waste management situation to reduce health risks associated with solid waste management during the COVID-19 pandemic. 


\section{Description of the study area}

Tehran City was selected in this research, as the capital and the most urbanized city of Iran. Tehran with the area of 730 $\mathrm{km}^{2}$ is located at latitude and longitude of $35.6944^{\circ} \mathrm{N}$ and $51.4215^{\circ} \mathrm{E}$, respectively. It is one of the largest cities in West Asia and the 21 st largest city in the world with a population of $8,693,706$. The city is divided into 22 municipal districts. The total annual rainfall and evaporation are $233 \mathrm{~mm}$ and $250 \mathrm{~mm}$, respectively. The elevation above sea level of this region varies from 1020 to $1060 \mathrm{~m}$, and the average annual temperature varies between -5 and $40{ }^{\circ} \mathrm{C}$. Aradkouh waste processing and disposal site (formerly known as Kahrizak disposal site) that is located $40 \mathrm{~km}$ to the south of the city has been the main waste disposal site of Tehran for several decades. Separation, composting, incineration and landfilling of the Tehran's MSW are all conducted in the Aradkouh complex.

\section{Results and discussion}

\section{Emerging environmental issues during the COVID-19 outbreak}

COVID-19 may pose different direct and indirect effects on the environment. Initial reports suggested some positive impacts of COVID-19 pandemic on the environment mainly because of reduced energy consumption. For instance, halted activity of some power plants and industrial sectors as well as reduced use of vehicles resulted in a drastic reduction in emission of $\mathrm{CO}_{2}, \mathrm{NO}_{2}$ and $\mathrm{PM}_{2.5}$ in China, though such a short-term reduction in emission of pollutant and greenhouse gases due to outbreak of the COVID-19 would not be a sustainable approach to protect the environment [8]. Air quality indexes in Tehran were also improved during initial stages of the COVID-19 pandemic. In addition, reduction in commercial activities and decreased use of private and public transportation reduced noise levels in Tehran. However, as time goes on, many people have gradually returned back to the normal life. Presently, most of the businesses including restaurants have been reopened in Tehran. The government regularly encourage residents to practice social distancing measures, though there are not strict regulations to enforce them wearing facemasks and following social distancing guidelines in most public places. Up to $62 \%$ and $23 \%$ of the Tehranian residents followed social distancing guidelines and used PPEs during March and April, respectively. Currently only $11 \%$ of the residents follow the recommended measures. As a result, the only impressive positive effect of the COVID-19 outbreak on the environment i.e. reduced emission of air pollutants and greenhouse gases have disappeared quickly and this large city is now facing with several environmental challenges associated with outbreak of the COVID-19 such as increased use of private vehicles rather than public transportation, elevated consumption of water, and enhanced load of detergents in domestic wastewaters in Tehran. Among the various environmental issues, solid waste management is the most challenging environmental problem in Tehran during COVID-19 pandemic.

\section{Impact of the COVID-19 pandemic on MSW generation in Tehran}

The average MSW generation rate is $0.745 \mathrm{~kg} / \mathrm{capita} /$ day in Iran, with the highest rate of up to $1.0-1.2 \mathrm{~kg} /$ capita/day in Tehran. The quantity of the solid waste generated in Tehran is estimated to be more than 7500 tonnes per day. According to statistical data, more than one-fifth of the total MSW in Iran is generated in Tehran [9, 10]. Typical composition of municipal solid wastes in Tehran is shown in Fig. 2. Food and vegetable residues constitutes the major fraction of

Fig. 2 Composition of different wastes in collected municipal solid waste of Tehran (\%)

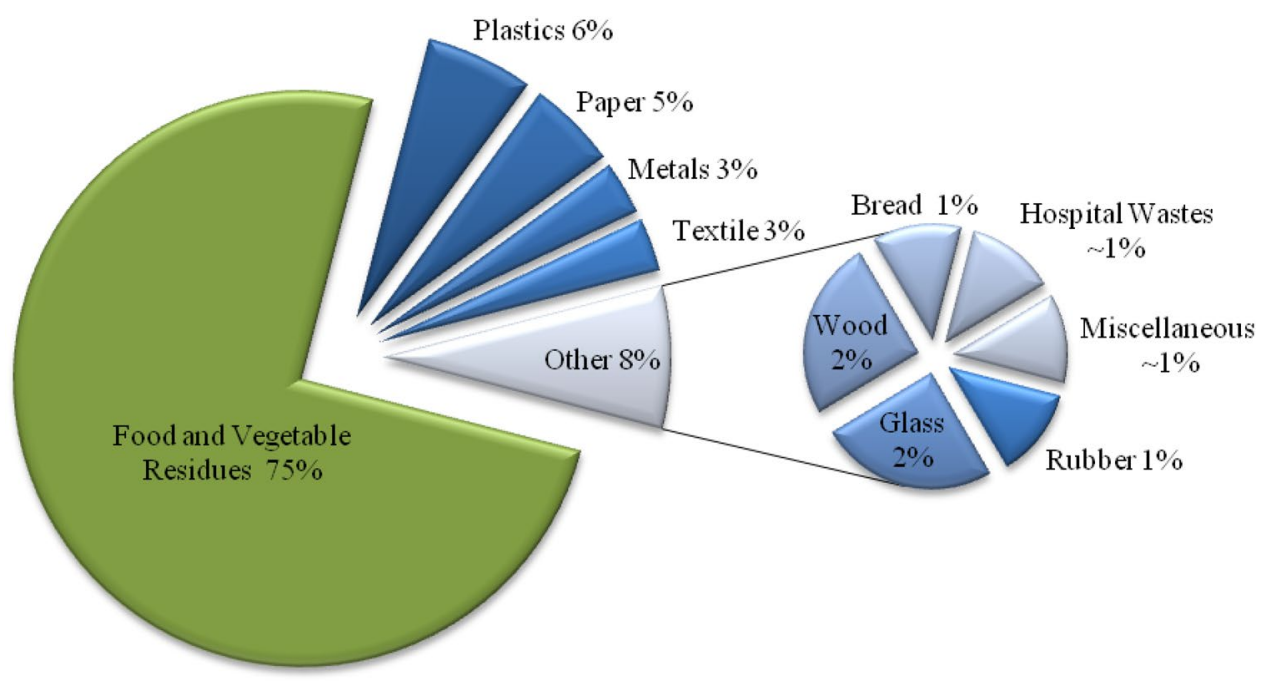


wastes $(75 \%)$. Hospitals generate about $1 \%$ of the MSW in Tehran (Fig. 2). COVID-19 outbreak in Iran has changed the quantity and composition of solid wastes in most parts of the country including Tehran City.

WHO and other national disease control centers have issued different guidelines in order to reduce the spread of Coronavirus from human to human. In Iran, the use of personal protective equipments (PPE) such as facemasks has been recommended by the Iran's National Headquarters for Managing Coronavirus (INHMC) for all people. The INHMC was formed by the Ministry of Health and Medical Education to prevent or control the outbreak of Coronavirus in Iran. The INHMC is expected to provide medical and pharmaceutical services, establish relevant policies, and disseminate educational materials to the public, physicians, medical teams and hospital staff. In addition, necessary administrative measures should be considered and all governmental and private organizations and sectors including the district municipalities must collaborate with the INHMC to face with the COVID-19 pandemic. The INHMC recommended the medical service workers (e.g. physicians, nurses, etc.) and all caregivers for COVID-19 patients to use single-use gloves, tissues, aprons and facemasks. Many other service workers such as barbers, cooks, taxi and bus drivers, street sweepers and waste collection workers have been commended to use facemasks and/or single-use gloves. A large amount of these PPE is daily used in Tehran during the COVID-19 pandemic as a result of such recommendations. On average ca. $26 \%$ of the residents of Tehran have accepted to use PPEs during the pandemic that is pretty low in the context of the spread of the viral disease. The INHMC is trying to oblige all residents to use facemasks in public places through legislation. The estimated figures of facemasks and single-use plastic gloves discarded daily in Tehran based on the two scenarios (i.e. according to the legislation situation) are presented in Table 1. The highest amount of the facemask wastes were generated during March 2020 (10.78 million per day). Significant increase in the price of the PPEs in Iran after the outbreak of COVID-19 would be an influential factor discouraging people to use them. Presently, more than 1.9 million facemasks and 3.8 million plastic gloves are being discarded in Tehran each day. Table 1 indicates that legislation will considerably increase discarded facemasks, while the number of used gloves may remain constant.

Many of the people discard their used PPEs in the street or sewers that could increase the spread of the viral disease and endanger public health, especially for street sweepers and waste scavengers. In general, the volume and weight of the generated wastes in Tehran has increased since the outbreak of the COVID-19 not only due to the increase in the plastic wastes, but also because of changing people's habits. As people usually spend more time in their homes during the COVID-19 time, they produce more wastes. For instance, Tehranian residents have produced more food wastes and utilized greater amount of detergents. In addition, online shopping and food delivery have increased remarkably in Tehran. Packaging wastes from detergents and disinfection agents such as HDPE and PET has dramatically increased in Tehran City's waste stream during the COVID-19 pandemic. Based on the literature human coronaviruses such as Severe Acute Respiratory Syndrome (SARS) coronavirus and Middle East Respiratory Syndrome (MERS) coronavirus can survive on the non-living surfaces such as metals and plastics for up to 9 days [11]. Therefore single-use plastics are preferred by most individuals as a safe alternative. Lock-down measures in Tehran was another reason for an increase in the consumption of packaging materials, which are extensively being used by restaurants and grocery stores for the delivery of food and other items to customers. In the meantime, discarded PPEs can exacerbate environmental and health issues, if not handled safely. These environmental hazards are usually greater in developing countries with poor waste management systems. As an example, waste collection trucks in Tehran are mainly equipped with compactors which enable them to collect greater quantity of refuses. Compaction of refuses is economically attractive for private

Table 1 Estimated daily use of facemasks and single-use plastic gloves in Tehran City during the COVID-19 pandemic

\begin{tabular}{|c|c|c|c|c|c|c|}
\hline \multirow[t]{2}{*}{ Factor } & \multicolumn{5}{|c|}{ During the pandemic (Before legislation) } & \multirow{2}{*}{$\begin{array}{l}\text { During the pandemic } \\
\text { (After prospective legis- } \\
\text { lation) }\end{array}$} \\
\hline & March 2020 & April 2020 & May 2020 & June 2020 & Average & \\
\hline Facemask acceptance rate $(\%)$ & 62 & 23 & 11 & 9 & 26 & 100 \\
\hline Average daily facemask per capita & 2 & 2 & 2 & 2 & 2 & 2 \\
\hline Discarded facemasks per day* & $10,780,196$ & $3,999,105$ & $1,912,616$ & $1,564,867$ & $4,520,728$ & $17,387,412$ \\
\hline Gloves acceptance rate $(\%)$ & 62 & 23 & 11 & 9 & 26 & 9 \\
\hline Average daily gloves per capita** & 4 & 4 & 4 & 4 & 4 & 4 \\
\hline Discarded plastic gloves per day & $21,560,391$ & $7,998,210$ & $3,825,231$ & $3,129,734$ & $9,041,456$ & $3,129,734$ \\
\hline
\end{tabular}

*Calculation method adapted from Nzediegwu and Chang [6]

**Lower quality and durability of single-used gloves in Iran after the COVID-19 pandemic would increase the required number of gloves in the future 
contractors; though overflow of the produced leachate from waste collection trucks is a common phenomenon in Tehran due to the high moisture content of the collected wastes. There is no restriction or recommendation on the proper use of compactors of garbage trucks during the COVID-19 outbreak in Iran. Viruses may persist in landfill leachates for days to months [12]. Continuation of this strategy for collection of wastes in Tehran may introduce a new route for propagation of the Coronavirus.

\section{Impact of the COVID-19 pandemic on MSW collection system}

Tehranian residents are responsible to carry their household wastes to the nearest communal collection bulk bin (with the capacity of ca. $1 \mathrm{~m}^{3}$ ). Discarded materials have been collected through curbside collection schemes, before and after the outbreak of COVID-19. Waste Management Organization of Tehran Municipality (WMOTM) is responsible for collection of municipal solid wastes in Tehran. Segregation of solid wastes from the source is not practiced in most parts of Tehran; therefore the generated wastes are collected on daily basis to avoid purification of organic wastes. Each collection team is equipped with a waste collection truck, a driver and two labors. Generally, $7 \%$ of the produced MSW in Tehran is separated legally (3\% from the source and $4 \%$ at Aradkouh disposal center), while $10 \%$ of the total generated waste is illegally separated for recycling by waste keepers. After the outbreak of COVID-2019 in Tehran, the WMOTM was obliged to work under the supervision of the INHMC. Legal separation and recycling of urban wastes have been suspended after the outbreak of Coronavirus in Tehran, whereas illegal segregation and recycling of wastes is still ongoing. Lack of strict regulation to avoid extensive separation of MSW by waste pickers would exacerbate health impacts of illegal separation and recycling of materials during the COVID-19 pandemic. Suspension of waste separation and recycling programs in Tehran was due to the threat of further propagation of the new Coronavirus at waste transfer stations and recycling facilities. However, waste separation during the COVID-19 pandemic had been reported to be more important than ever. Only generated wastes by infected or suspicious households must be exempted. For instance, Italy has banned source separation of wastes by only the infected residents [8]. Right before the COVID-19 pandemic, a pilot source separation program had launched for residential, commercial and intuitional areas of the districts of 6,21 and 22 of Tehran, where people were asked to store their wastes in three sealed, labeled containers. Organic wastes were collected every other day, while separated recyclable wastes such as paper, plastics and metals were collected once or twice a week. Residents were paid by the WMOTM, based on the weight of the collected recycled wastes, to promote their participation in the source separation program. This pilot program was also stopped due to the COVID-19 pandemic. Except this pilot program, waste collection procedure in Tehran has not been subjected to a significant change during the COVID-19 outbreak.

\section{MSW disposal in Tehran after the outbreak of Coronavirus}

Collected wastes in Tehran are transported to the 11 designated transfer stations throughout the city, and then transferred to the Aradkouh disposal site, where they undergone various processes including separation, composting, incineration or landfilling before the outbreak of COVID-19. Previously around 4900 tonnes of the collected wastes were daily buried/landfilled in Tehran. Moreover, around 200 tonnes of the collected wastes were incinerated everyday at Aradkouh disposal site. Incineration of hazardous wastes such as hospital wastes is technically possible at Aradkouh disposal center, but associated disposal costs will dramatically go up, and none of the authorized organizations would take this financial responsibility. Incineration cost of medical wastes in China was estimated to be 20-30 times higher than that of urban wastes, because treatment and emission control systems designed for general waste quality have to be altered dramatically. For example, waste incineration temperature in Germany is required to be set at $1000^{\circ} \mathrm{C}[13]$ and WHO recommends treating healthcare wastes at temperatures between 900 and $1200{ }^{\circ} \mathrm{C}$ [14]. Composting facility of Aradkouh was also working with the nominal capacity of 3500 tonnes per day. Incineration and composting of municipal solid wastes at Aradkouh disposal site have been completely ceased due to the COVID-19 pandemic by the order of INHMC. Likelihood of health risks due to manual separation of solid wastes to provide incinerator feed was a major reason for this decision, while incineration of wastes would be a reliable treatment method to destroy viruses including the new Coronavirus. All the collected MSW in Tehran are now being buried/ landfilled at Aradkouh disposal site (approximately 7500 tonnes per day), without undergoing any further process. Landfilling of wastes in Tehran has increased by $34.7 \%$ after the outbreak of Coronavirus.

\section{Hospital waste management in Tehran during the COVID-19 pandemic}

Tehran has 165 hospitals with 26,444 active beds. In Iran, hospital wastes are categorized in three groups: non-hazardous such as food residues, infectious including sharp objects (e.g. Syringes and hypodermic needles) and chemical/pharmaceutical wastes. In 2016, 91.2 tonnes of hospital wastes produced daily in Tehran $(3.44 \mathrm{~kg} /$ day $/ \mathrm{bed})$ containing 52.6, 34.6 and 4.0 tonnes of, respectively, non-hazardous, 
infectious, and chemical/pharmaceutical wastes. Hospital wastes produced in Tehran have to be collected in four distinct groups: non-hazardous (black bags), infectious (yellow bags), sharp (safety boxes) and pharmaceutical/chemical wastes (white or brown bags), which has been satisfactory followed only by $47.3 \%$ of the hospitals. Approximately $37.9 \%$ of the total wastes generated at Tehran's hospitals were infectious before the COVID-19 pandemic, which is significantly greater than WHO estimated value for hospitals $(<15 \%)$. Insufficient programs on separation of hospital wastes has increased the generation rate of infectious wastes and associated treat $[15,16]$.

Medical wastes collected from Tehran's hospitals varied between 52 and 74 tonnes per day from March 2019 to January 2020, with an average of 68 tonnes per day. COVID19 pandemic enhanced generation of hospital wastes to 80-110 tonnes per day in Tehran. In February 2019 only six hospitals were allocated to the COVID-19 patients in Tehran, which were then drastically increased to 149 hospitals throughout the city. Direct correlation between the number of Coronavirus infected persons and daily amount of hospital wastes generated in Tehran was found during the COVID-19 pandemic. Hospital waste generation increased by 12-22 tonnes per day between late-February 2020 and mid-March 2020 compared to the pre-pandemic situation, then hit a plateau of 110 tonnes per day during the first peak of COVID-19 between late-March 2020 and April 2020 (42 tonnes per day more than pre-pandemic situation). Overall, hospital waste generation in Tehran has increased by 17.6-61.8\% due to the COVID-19 pandemic, which is much less than the dramatic increase of medical wastes in Hubei, China (370\% increase) during the pandemic [13]. People with mild symptoms of Coronavirus are mainly self-isolated and generate infectious wastes, which are being introduced to the urban waste stream. Moreover, medical wastes produced at suspicious places such as nursery homes and small healthcare centers are not included in the figures for Tehran.

Before the outbreak of COVID-19, infectious and sharp wastes produced in hospitals were supposed to be rendered non-hazardous at hospitals. 155 out of 165 hospitals in Tehran have some treatment equipments. Non-incineration methods had been the dominant techniques practiced in these hospitals including autoclave, hydroclave and chemical treatment, before the outbreak of the new Coronavirus. Non-infectious hospital wastes were treated as regular MSW before the outbreak of the COVID-19. About $80 \%$ of the produced chemical and pharmaceutical wastes were also collected by private contractors. In general, collected wastes from the hospitals (treated or untreated) were commingled with general urban wastes and transferred to the Aradkouh disposal site [16]. Treatment of infectious wastes at hospitals has been paused after the COVID-19 outbreak. Six distinct trucks have been considered by the WMOTM to collect only the COVID-19-related wastes from the hospitals, which do not seem to be sufficient to serve 149 hospitals. In addition, currently all hospital wastes are being mixed together without undergoing any treatment or process, then collected in double or triple bags and transferred to the Aradkouh disposal site to be buried in designated trenches. Such a hasty decision-making in management of hospital wastes in developing countries is comprehensible at early stages of the COVID-19 outbreak, but its continuation after several months is not justifiable technically and environmentally. Generation of chemical and pharmaceutical wastes has not increased significantly during the COVID-19 pandemic (up to 1 tonnes per day), and they are still being collected separately by private contractors. In addition to the hospitals, there are around 3000 small healthcare centers in Tehran which may produce COVID-19-related wastes and currently there is no program to observe and manage their medical wastes properly. Medical wastes produced at homes, small healthcares such as clinics and nursing homes of Tehran are being collected and managed in accompany with general urban wastes. To date, the responsible authorities such as INHMC have not issued an integrated protocol for medical waste management in large cities during the COVID-19 pandemic.

\section{Conclusions}

This research raises important concerns on emerging challenges in management of MSW due to the COVID-19 pandemic in Tehran, as one of the largest and densely-populated cities in the world. Logistical challenges have been created for MSW management in Tehran after the outbreak of new Coronavirus, while other environmental, technical and financial issues have also taken a back seat during COVID-19 crisis. Further contagion from improper solid waste management is probable in developing countries such as Iran. In the meantime, sudden increase in the price of PPEs in Iran has forced low-income residents to completely disregard using the PPEs that might boost the spread of the viral disease. Governmental supports are required in this regard and the public health should be prioritized over all other considerations during the COVID-19 pandemic. There is a significant uncertainty over the economic recovery path in most developing nations including Iran, and there might be an alteration in people habits, which in turn affects MSW generation that should be addressed in future works. Substantial structural modification in waste management in Tehran is required, from the separation and storage guidelines at homes and hospitals to the safety protocols for waste collection teams during the pandemic. Safe separation, handling and disposal of MSW including medical wastes from hospital and nonhospital sources should be highlighted as a national priority. 
Neglecting the effects of the COVID-19 pandemic on people behavior and solid waste management systems would pose more challenging and long-lasting environmental and health outcomes in developing countries. Based on the findings, a few urgent pragmatic remarks are prioritized to promote proper management of urban wastes during the pandemic:

- Devising and implementing strict regulations on management of potentially hazardous wastes such as discarded PPEs and medical wastes.

- Long-term waste management schemes based on different scenarios for the COVID-19 pandemic in the future should be pondered, incorporating the socioeconomic factors and uncertainties.

- Provision of enforceable and observable plan for collection, processing, transfer and final disposal of the infectious wastes of hospitals.

- High quality PPEs should be distributed expensively among the residents with affordable price and proper guideline for collection of the used PPEs should be prepared.

- Special waste collection bins should be provided in large buildings in residential, commercial, institutional, governmental and healthcare centers and in other public places such as metro stations for discarding used PPEs. Such collection buckets should be emptied on daily basis by trained personnel.

- Allocation of sufficient budget to supply the hospitals with appropriate treatment equipments to avoid burial of untreated infectious wastes.

- Identifying small healthcare centers and suspicious residents producing COVID-19 wastes to be able to collect and manage their medical wastes apart from the general MSW

- COVID-19 patients (and their family members) who receive care at home should be provided with sufficient training and their produced wastes must be collected separately in tightly closed double bags.

- Promoting the knowledge and attitude of medical service workers and caregivers to the COVID-19 patients towards safe storage and disposal of all potentially hazardous wastes including infectious wastes and used PPEs through training programs.

- Taking advantage of national and especially social media capacities to promote knowledge and attitude of people towards proper waste management programs during the COVID-19 pandemic.

Involvement of the environmental and human health effects of the COVID-19 pandemic will be inevitable in planning of sustainable solid waste management strategies for the upcoming few years. Developing countries with generally less developed waste management infrastructures are required to put significant effort into building up capacities to cope with this emerging crisis.

Acknowledgements The authors would like to thank the University of Tehran for the support for this research.

\section{Compliance with ethical standards}

Conflict of interest The authors would like to declare that there are no conflicts of interest for publication of this paper.

\section{References}

1. WHO (2020a) Coronavirus disease (COVID-19) situation report-179. World Health Organization, pp 1-18. Accessed 18 Jul 2020

2. Zareie B, Roshani A, Mansournia MA, Rasouli MA, Moradi G. A Model for COVID-19 Prediction in Iran Based on China Parameters. Arch Iran Med 23(4):244-248. https://doi.org/10.34172/ aim.2020.05

3. Wan H, Cui J, Yang GJ (2020) Risk estimation and prediction by modeling the transmission of the novel coronavirus (COVID-19) in mainland China excluding Hubei province. medRxiv. https:// doi.org/10.1101/2020.03.01.20029629

4. Zhang KK, Xie L, Lawless L, Zhou H, Gao G, Xue C (2020) Characterizing the transmission and identifying the control strategy for COVID-19 through epidemiological modeling. medRxiv. https:// doi.org/10.1101/2020.02.24.20026773

5. Rothan HA, Byrareddy SN (2020) The epidemiology and pathogenesis of coronavirus disease (COVID-19) outbreak. J Autoimmun 2020:102433

6. Nzediegwu C, Chang SX (2020) Improper solid waste management increases potential for COVID-19 spread in developing countries. Resour Conserv Recycl 161:104947

7. Rupani PF, Maleki Delarestaghi R, Asadi H, Rezania S, Park J, Abbaspour M, Shao W (2019) Current scenario of the Tehran municipal solid waste handling rules towards green technology. Int J Env Res Public Health 16:979

8. Zambrano-Monserrate MA, Ruano MA, Sanchez-Alcalde L (2020) Indirect effects of COVID-19 on the environment. Sci Total Environ 2020:138813

9. Daryabeigi Zand A, Vaezi Heir A, Hoveidi H (2019) Comparative evaluation of unmitigated options for solid waste transfer stations in North East of Tehran using rapid impact assessment matrix and Iranian Leopold matrix. Environ Energ Economic Res 3:189-202

10. Esmaeilizadeh S, Shaghaghi A, Taghipour H (2020) Key informants' perspectives on the challenges of municipal solid waste management in Iran: a mixed method study. J Mater Cycles Waste Manag 22:1284-1298

11. Kampf G, Todt D, Pfaender S, Steinmann E (2020) Persistence of coronaviruses on inanimate surfaces and their inactivation with biocidal agents. J Hosp Infect 104:246-251

12. U.S. EPA (2016) Evaluation of Persistence of Viruses in Landfill Leachate. US Environmental Protection Agency, Washington, DC, EPA/600/R-16/368

13. Klemeš JJ, Van Fan Y, Tan RR, Jiang P (2020) Minimising the present and future plastic waste, energy and environmental footprints related to COVID-19. Renew Sust Energ Rev 127:109883

14. WHO (2020b) Treatment and disposal technologies for healthcare waste. https://www.who.int/water_sanitation_health/medicalwas te/077to112.pdf. Accessed 18 Jul 2020 
15. Eslami A, Nowrouz P, Sheikholeslami S (2017) Status and challenges of medical waste management in hospitals of Iran. Civil Eng J 3:741-748

16. Gitipour S, Eskanroud AP, Firouzbakht S (2017) Evaluation of medical waste management in Tehran hospitals. Environ Stud 42:709-718

17. Worldometers (2020) Worldmeter COVID-19 Data: Iran. https:// www.worldometers.info/coronavirus/country/iran/. Accessed 18 Jul 2020
Publisher's Note Springer Nature remains neutral with regard to jurisdictional claims in published maps and institutional affiliations. 